\title{
The respiratory health benefits of quitting cannabis use
}

\author{
Donald P. Tashkin \\ Affiliation: Division of Pulmonary and Critical Care Medicine, David Geffen School of Medicine at UCLA, Los \\ Angeles, CA, USA.
}

Correspondence: Donald P. Tashkin, Dept of Medicine, David Geffen School of Medicine at UCLA, 10833 Le Conte Ave., Los Angeles, CA 90095, USA. E-mail: Dtashkinamednet.ucla.edu

-

@ERSpublications

Quitting cannabis smoking and the effects on respiratory symptoms

http://ow.ly/MTU6R

Cannabis is the second most widely smoked substance besides tobacco. Moreover, its use in some societies has increased over the past several years [1], possibly due to changing perceptions regarding its potentially deleterious effects on health and its putative health benefits [2], as reflected by decriminalisation and legalisation for medicinal or recreational use by some regulatory authorities. A limited number of observational studies have examined the effects of cannabis on respiratory health [3-9]. These have nearly uniformly demonstrated an association between cannabis use and symptoms of chronic bronchitis [3-7, 9], particularly chronic cough and sputum production, with more variable effects on wheezing and generally negative effects on breathlessness. In addition, there is some evidence of an association with acute bronchitic episodes [3] and increased healthcare utilisation for acute respiratory illness [10]. Findings from a couple of these studies have also suggested additive effects of cannabis and tobacco smoking on symptoms of chronic bronchitis $[4,8]$.

The link between cannabis use and chronic bronchitis is probably attributable to the injurious effects of cannabis smoke on the respiratory epithelium of the larger airways, as demonstrated by videobronchoscopy [11] and bronchoscopic biopsies [12]. Regular smokers of cannabis with or without concomitant tobacco exhibit tracheobronchial oedema and erythema along with increased secretions [11], with biopsy evidence of replacement of damaged ciliated epithelium by hyperplastic mucus-secreting goblet cells and reserve cells along with squamous metaplasia [12]. Moreover, combined use of both cannabis and tobacco appears to have an additive effect on these histopathological alterations in the bronchial epithelium [12]. Goblet cell hyperplasia along with loss of ciliated bronchial epithelial cells in regular cannabis smokers may be responsible for the bronchitic symptoms as a consequence of increased production of mucus by the mucus-secreting epithelial cells and the accompanying impairment in mucociliary escalator function, leaving cough as an alternative mechanism for cleansing the airway of the accumulated mucus.

In contrast to the effect of regular cannabis use on respiratory symptoms, most studies have failed to find an association between cannabis and chronic airflow obstruction after adjusting for the effect of tobacco $[3,7-10,13,14]$. However, in the few studies in which whole body plethysmography was used, an association has been found between cannabis and a modest increase in airway resistance or decrease in specific airway conductance $[3,7,15]$, probably reflecting the impact of cannabis on airway wall oedema in the larger airways. Moreover, in a few studies, cannabis has been shown to be associated with hyperinflation and/or an increase in forced vital capacity (FVC) $[9,13,14]$, possibly due to stretching the lung as a result of the deep inhalation technique and prolonged breath-holding time characteristic of cannabis smoking. The increase in FVC may account for the reduction in forced expiratory volume in $1 \mathrm{~s}$

Received: March 022015 | Accepted: March 042015

Conflict of interest: Disclosures can be found alongside the online version of this article at erj.ersjournals.com

Copyright @ERS 2015 
$\left(\mathrm{FEV}_{1}\right) / \mathrm{FVC}$ ratio observed in a couple of studies $[4,5,9]$, challenging the view that the reduced $\mathrm{FEV}_{1} /$ FVC ratio is indicative of airflow obstruction in these studies.

The reasons for the disparity between the comparatively minor if any impact of habitual cannabis use on airflow obstruction and its nearly uniform association with symptoms of chronic bronchitis are unclear. A speculative hypothesis for the general lack of association of cannabis use with chronic airflow obstruction is that the well-documented anti-inflammatory effects of delta-9-tetrahydrocannabinol (THC) [16-18] could possibly provide protection against the pro-inflammatory effects of the noxious non-THC components in cannabis smoke that are similar to those found in tobacco smoke [19-21].

While it is not clear whether the presence of symptoms of chronic bronchitis in smokers of cannabis might or might not be a motivating factor to quit smoking cannabis, it certainly is of interest to know whether or not these symptoms resolve upon discontinuation of cannabis use. Such a result of quitting cannabis use would be expected by analogy with reports that cessation of tobacco smoking results in an improvement in chronic cough, sputum and wheeze, in contrast to the persistence of these symptoms in continuing tobacco smokers [22-24]. Only a single previous study addressed this question in cannabis users by analysing respiratory symptom data from a longitudinal study of respiratory status in a convenience sample of 299 young adults who habitually smoked marijuana and/or tobacco or never smoked either substance and were followed over a mean of 9.8 years [25]. Those who continued to smoke either substance were at a significantly increased risk of having symptoms of chronic bronchitis at follow-up compared with those who quit smoking, while the quitters of either cannabis or tobacco had no greater likelihood of having chronic bronchitic symptoms than never-smokers.

The paper by Hancox et al. [26] in the current issue of the European Respiratory Journal addresses a similar question using a more detailed analysis of data from a large, well-characterised cohort of nearly 1000 subjects followed from birth to age 38 years with assessments of respiratory symptoms at ages 18,21 , 26, 32 and 38 years to determine the effects of quitting frequent (at least weekly) cannabis use (or of reducing cannabis use to less than weekly) on chronic respiratory symptoms after controlling for the effects of concomitant tobacco use and other influential variables, including asthma. The numbers of frequent cannabis users in this birth cohort included 157, 162, 138 and 99 at ages 21, 26, 32 and 38 years, respectively, compared with 540, 487, 608 and 703 non-users, respectively. The authors found strongly significant associations of current cannabis use with morning cough, sputum production and wheeze, but not exertional dyspnoea, over multiple assessments of these subjects at different ages. While the numbers of quitters of cannabis between the different assessments were comparatively small $(26,52,54$ and 50 , respectively), the authors were able to observe significant reductions in cough, sputum and wheeze in the quitters compared with the continuing smokers, irrespective of whether the analysis was confined to smokers of cannabis alone or to those who smoked tobacco along with cannabis. Moreover, the symptoms in the quitters were reduced to levels roughly similar to those reported by the non-users.

The authors' observation that dual smokers of both cannabis and tobacco experienced reductions in symptoms of chronic bronchitis after discontinuation of cannabis alone suggests that the effects of cannabis on respiratory symptoms may have been additive to those of tobacco, consistent with the results of some [4, 8] but not other [3, 7] studies. Interestingly, the proportion of cannabis quitters with self-reported cough and sputum who continued to smoke tobacco declined to levels not very different from the proportion of the nonsmokers who reported these symptoms. This observation is surprising, since smoking of tobacco alone has been well documented to be associated with symptoms of chronic bronchitis [3-8]. This finding is even more surprising because of the observation that at least half of the cannabis quitters who had smoked tobacco along with cannabis reported increased use of tobacco after quitting cannabis. Perhaps the very small numbers of quitters might account for these unexpected findings.

Bronchoscopic evidence of goblet cell hyperplasia and loss of ciliated bronchial epithelial cells in smokers of cannabis alone [12] might account for their bronchitic symptoms, but no bronchoscopic studies have been carried out in quitters of cannabis to investigate whether the improvement in respiratory symptoms might be correlated with repair of the associated bronchial epithelial histopathology. Only a few studies, largely cross-sectional, provide data pertaining to possible effects of tobacco smoking cessation on airway pathology in smokers with chronic bronchitis [27]. The greatest change has been a reduction in goblet cell hyperplasia in central, but not peripheral, airways, consistent with a reduction in mucus hypersecretion and symptoms of chronic bronchitis [27]. These findings suggest that a similar mechanism might explain the resolution of bronchitic symptoms following cessation of cannabis use.

An important question that the study of HANCOX et al. [26] was unable to cover was the extent to which the presence of chronic respiratory symptoms might have been a factor in motivating frequent cannabis users to quit smoking cannabis. This question has previously been addressed in a convenience sample of 
104 adult cannabis smokers (mean age 35 years) who reported at least one serious attempt to quit smoking [28]. Based on responses to a structured questionnaire, their reasons for quitting were primarily motivated by concerns about cannabis-related health problems, as well as about the impact of marijuana smoking on their self-image and social acceptability. These reasons for quitting differed from those reported by adolescents, who were mainly motivated to quit in order to avoid legal problems, obtain a job or circumvent a positive drug test [29]. A better understanding of whether annoying respiratory symptoms motivate cannabis users to quit may help in efforts at prevention and treatment of cannabis abuse and dependence through communication of the beneficial effects of quitting cannabis in resolving these symptoms.

\section{References}

1 Substance Abuse and Mental Health Services Administration. Results from the 2012 National Survey on Drug Use and Health: Summary of National Findings. NSDUH Series H-46, HHS Publication No. (SMA) 13-4795. Rockville, Substance Abuse and Mental Health Services Administration, 2013.

2 Johnston LD, O’Malley PM, Bachman JG, et al. Monitoring the Future. National Survey Results on Drug Use, 1975-2013. Volume 1: Secondary School Students. Ann Arbor, Institute for Social Research, The University of Michigan, 2014.

3 Tashkin DP, Coulson AH, Clark VA, et al. Respiratory symptoms and lung function in habitual heavy smokers of marijuana alone, smokers of marijuana and tobacco, smokers of tobacco alone, and nonsmokers. Am Rev Respir Dis 1987; 135: 209-216.

4 Bloom JW, Kaltenborn WT, Paoletti P, et al. Respiratory effects of non-tobacco cigarettes. Br Med J 1987; 295: $1516-1518$.

5 Taylor DR, Poulton R, Moffitt TE, et al. The respiratory effects of cannabis dependence in young adults. Addiction 2000; 95: 1669-1677.

6 Moore BA, Augustson EM, Moser RP, et al. Respiratory effects of marijuana and tobacco use in a US sample. $J$ Gen Intern Med 2005; 20: 33-37.

7 Aldington S, Williams $\mathrm{M}$, Nowitz $\mathrm{M}$, et al. Effects of cannabis on pulmonary structure, function and symptoms. Thorax 2007; 62: 1058-1063.

8 Tan WC, Lo C, Jong A, et al. Marijuana and chronic obstructive lung disease: a population-based study. CMAJ 2009; 180: 814-820.

9 Kempker JA, Honig EG, Martin GS. The effects of marijuana exposure on expiratory airflow. A study of adults who participated in the US National Health and Nutrition Examination Study. Ann Am Thorac Soc 2015; 12: 135-141.

10 Polen MR, Sidney S, Tekawa IS, et al. Health care use by frequent marijuana smokers who do not smoke tobacco. West J Med 1993; 158: 596-601.

11 Roth MD, Arora A, Barsky SH, et al. Airway inflammation in young marijuana and tobacco smokers. Am J Respir Crit Care Med 1998; 157: 928-937.

12 Fligiel SE, Roth MD, Kleerup EC, et al. Tracheobronchial histopathology in habitual smokers of cocaine, marijuana, and/or tobacco. Chest 1997; 112: 319-326.

13 Hancox RJ, Poulton R, Ely M, et al. Effects of cannabis on lung function: a population-based cohort study. Eur Respir J 2010; 35: 42-47.

14 Pletcher MJ, Vittinghoff E, Kalhan R, et al. Association between marijuana exposure and pulmonary function over 20 years. JAMA 2012; 307: 173-181.

15 Tashkin DP, Calvarese BM, Simmons MS, et al. Respiratory status of seventy-four habitual marijuana smokers. Chest 1980; 78: 699-706.

16 Roth MD, Baldwin GC, Tashkin DP. Effects of delta-9-tetrahydrocannabinol on human immune function and host defense. Chem Phys Lipids 2002; 121: 229-239.

17 Baldwin GC, Tashkin DP, Buckley DM, et al. Marijuana and cocaine impair alveolar macrophage function and cytokine production. Am J Respir Crit Care Med 1997; 156: 1606-1613.

18 Klein TW, Newton C, Larsen K, et al. The cannabinoid system and immune modulation. J Leukoc Biol 2003; 74 : 486-496.

19 Hoffmann D, Brunnemann KD, Gori GB, et al. On the carcinogenicity of marijuana smoke. In: Runeckles VC, ed. Recent Advances in Phytochemistry. New York, Plenum Press, 1975; pp. 63-81.

20 Novotný M, Merli F, Wiesler D, et al. Fractionation and capillary gas chromatographic-mass spectrometric characterization of the neutral components in marijuana and tobacco smoke condensates. J Chromatogr A 1982; 238: $141-150$.

21 Moir D, Rickert WS, Levasseur G, et al. A comparison of mainstream and sidestream marijuana and tobacco cigarette smoke produced under two machine smoking conditions. Chem Res Toxicol 2008; 21: 494-502.

22 Kanner RE, Connett JE, Williams DE, et al. Effects of randomized assignment to a smoking cessation intervention and changes in smoking habits on respiratory symptoms in smokers with early chronic obstructive pulmonary disease: the Lung Health Study. Am J Med 1999; 106: 410-416.

23 Etter JF. Short-term change in self-reported COPD symptoms after smoking cessation in an internet sample. Eur Respir J 2010; 35: 1249-1255.

24 US Dept of Health and Human Services. The Health Benefits of Smoking Cessation. A Report of the Surgeon General. DHHS Publication No. (CDC) 90-8416. Rockville, US Dept of Health and Human Services, Public Health Service, Centers for Disease Control, Center for Chronic Disease Prevention and Health Promotion, Office on Smoking and Health, 1990; pp. 285-296.

25 Tashkin DP, Simmons MS, Tseng CH. Impact of changes in regular use of marijuana and/or tobacco on chronic bronchitis. COPD 2012; 9: 367-374.

26 Hancox RJ, Shin HH, Gray AR, et al. Effects of quitting cannabis on respiratory symptoms. Eur Respir J 2015; 46: $80-87$. 
27 Willemse BW, Postma DS, Timens W, et al. The impact of smoking cessation on respiratory symptoms, lung function, airway hyperresponsiveness and inflammation. Eur Respir J 2004; 23: 464-476.

28 Copersino ML, Boyd SJ, Tashkin DP, et al. Cannabis withdrawal among non-treatment-seeking adult cannabis users. Am J Addict 2006; 15: 8-14.

29 Weiner MD, Sussman S, McCuller WJ, et al. Factors in marijuana cessation among high-risk youth. J Drug Educ 1999; 29: 337-357. 